\title{
Effects of simultaneously applied short-term transcutaneous electrical nerve stimulation and tactile stimulation on memory and affective behaviour of patients with probable Alzheimer's disease
}

\author{
E. Scherder, A. Bouma and L. Steen \\ Nursing Home St Jacob, Plantage Middenlaan 52, 1018 DH Amsterdam, The Netherlands
}

Correspondence to: E. Scherder, Veeteeltstraat 20, 1097 WV Amsterdam, The Netherlands

\begin{abstract}
In previous studies beneficial effects of peripheral electrical or tactile nerve stimulation were observed on memory and affective behaviour in patients with probable Alzheimer's disease. In the present study, it was investigated whether electrical and tactile stimulation applied simultaneously to Alzheimer patients would exceed the effects which were observed following treatment by each type of stimulation separately. Our data reveal that the simultaneous application of the two types of stimulation had a beneficial effect on non-verbal and verbal long-term recognition memory. In addition, patients who were treated participated more in activities of daily living, and were more interested in social contacts. In spite of these positive results, comparisons with those of previous studies suggest that a combination of electrical and tactile stimulation does not yield more effects than application of each type of stimulation separately.
\end{abstract}

Keywords: Affective behaviour - Alzheimer's disease - Memory - Short-term TENS -Tactile stimulation

\section{INTRODUCTION}

In three previous studies, patients in an early stage of probable Alzheimer's disease (AD) were treated with either peripheral electrical or tactile nerve stimulation during a 6 week period. In the first study, patients with AD were treated with peripheral electrical stimulation, i.e. transcutaneous electrical nerve stimulation (TENS) for $6 \mathrm{~h}$ per day (long-term TENS; Scherder et al., 1992). Patients who had undergone treatment improved not only in their ability to recall verbal material from long-term memory, but they also showed enhanced recognition performance when verbal material had to be held in store for a certain period of time. Moreover, these patients showed an enhancement in verbal fluency. Subsequently, other probable AD patients were treated with TENS for $30 \mathrm{~min}$ per day (short-term TENS; Scherder et al., 1994a). The results of that study suggest that shortterm TENS improved non-verbal short-term memory as well as non-verbal and verbal long-term recognition memory. In that study, the effects of short-term TENS on affective behaviour of $\mathrm{AD}$ patients were

(C) 1995 Rapid Communications of Oxford Ltd also examined. It was found that patients felt less depressed, more cheerful, and better tempered after treatment. Moreover, they were less withdrawn and participated more in activities of daily life. In a third study, tactile stimulation instead of electrical stimulation was applied to probable AD patients for $30 \mathrm{~min}$ per day. Compared to the short-term TENS study, tactile stimulation seemed to improve the same aspects of memory with an additional enhancement in verbal fluency (Scherder et al., 1995). The effects of tactile stimulation on affective behaviour (Scherder et al., 1994b) were similar to those observed after application of short-term TENS. Besides the abovementioned clinical studies, as far as we know no studies on the effects of peripheral nerve stimulation on memory or affective behaviour in $A D$ patients have been performed. We have hypothetized that the observed treatment effects may result from activation of brainstem areas, for example the locus coeruleus and nucleus raphe dorsalis, with subsequent activation of the hippocampus and hypothalamus. Evi- 
dence that both brainstem nuclei can be activated by peripheral nerve stimulation emanates from experimental studies on pain suppression (Huan-Ji and Yan-fang, 1976; Cedarbaum and Aghajanian, 1978; Jones and Gebhart, 1987). The rationale underlying our hypothesis is twofold. In the first place, it has been suggested that activation of the hippocampus by mild or strong tactile stimulation like stroking or pinching the animal may be mediated through both brainstem areas (Dudar et al., 1979; Dutar et al., 1985). Moreover, the increase in hippocampal activity under these circumstances was accompanied by a release of acetylcholine (Dutar et al., 1985). The hippocampus is highly involved in memory processes (Salzmann, 1992; Carpenter and Grossberg, 1993), and is affected in AD (Scheltens et al., 1992). The locus coeruleus and nucleus raphe dorsalis may also be involved in the activation of the hypothalamus by electro-acupuncture (Huan-Ji and Yan-fang, 1976), a type of peripheral electrical stimulation (Kaada, 1976). Both brainstem nuclei project to the hypothalamus (Bobillier et al., 1976; Legoratti-Sanchez et al., 1989; Vertes, 1991; Petrov et al., 1992), which plays an important role in affective behaviour of AD patients (Swaab et al., 1993; Raadsheer et al., 1994). In the second place, the locus coeruleus and nucleus raphe dorsalis, which are the sources of the noradrenergic and serotonergic neurotransmitter systems, respectively (Rossor, 1988; Saper, 1988), appear not to serve solely as a link between peripheral nerve stimulation and limbic areas. Several studies indicate that they also play a specific role in cognitive processes (Jacobs et al., 1981; Tucker and Williamson, 1984; Harley, 1987) and affective behaviour (Foote et al., 1983; Zweig et al., 1988).

So far, AD patients have been treated either with TENS or with massage. In the present study it was investigated whether simultaneous application of short-term TENS and massage exceeds the improvements in memory and affective behaviour in $\mathrm{AD}$ patients which were obtained by applying each type of stimulation separately.

\section{METHODS}

The sample consisted of 16 subjects drawn from a larger sample of 500 elderly persons who lived in a residential home for the elderly, ranging in age from 78 to 97 years, with a mean age of 85.8 years. The selection of the 16 subjects for this study was based on a progressive impairment of memory, in the absence of a history of psychiatric disorder, alcoholism, cerebral trauma, cerebrovascular disease, hydrocephalus, neoplasm, infection, epilepsy, kidney or lung diseases, disturbances of consciousness, or focal brain abnormalities. None of the subjects had a pacemaker. Level of cognitive functioning was assessed by using a Dutch cognitive screening test (CST; Deelman et al., 1989), a modified version of the Short Portable Mental State Questionnaire of Pfeiffer (Pfeiffer, 1975). The CST consists of 20 items evaluating recent and remote memory, personal orientation, and orientation in time and place. Subjects with a score 12 or less were classified as having a cognitive decline (maximum total score $=20$ ). The mean score of the CST in our sample was 10.2. The 16 subjects had completed elementary school.

The 16 subjects met the NINCDS-ADRDA criteria for the clinical diagnosis of probable Alzheimer's disease (McKhann et al., 1984). The clinical symptoms of the dementia had been present for at least 6 months. In addition, a score of 17 or less on the Hamilton Rating Scale for Depression was considered to indicate that the cognitive decline of the subjects was not due to depression (Hamilton, 1960). The mean score on the Hamilton Rating Scale of our sample was 7.

After this screening procedure, the subjects were divided into two groups of eight subjects: an experimental group and a control group. The subjects in the two groups were matched for age and performance on the CST. All subjects were informed extensively about the aim and procedure of this investigation (see below), but they were not told to which group they belonged. The subjects of the experimental group were familiarized with the combined treatment of tactile stimulation and short-term TENS by applying a trial treatment. The subjects of the control group were familiarized with a placebo treatment. The placebo treatment entailed application of a sham electro-stimulator, i.e. during the trial treatment no electrical current was applied. During the trial treatment of both the experimental and control group, no negative reactions of the subjects were observed, and the subjects and their family subsequently gave their informed consent. The family was informed about the course of the treatment on a weekly basis.

\section{Neuropsychological tests}

The 16 subjects underwent a number of neuropsychological tests in order to evaluate the effects of treatment on various aspects of memory, including verbal and visual short-term and long-term memory, and semantic memory. The test battery consisted of the following tasks.

(1) Digit Span from the Wechsler Memory Scale-Revised (WMS-R; Wechsler, 1984). This test was used to assess patients' verbal short-term memory abilities. 
TABLE I. The Behaviour Inventory: 12 main traits, consisting of 44 items

\begin{tabular}{|c|c|c|}
\hline $\begin{array}{l}\text { Depression } \\
\text { dejected } \\
\text { gloomy } \\
\text { appetite }\end{array}$ & $\begin{array}{l}\text { Anger } \\
\text { angry } \\
\text { aggressive }\end{array}$ & $\begin{array}{l}\text { Conscience } \\
\text { patient } \\
\text { attentive } \\
\text { concentrated }\end{array}$ \\
\hline complaining about physical discomfort & $\begin{array}{l}\text { Tiredness } \\
\text { drowsy }\end{array}$ & Indifference \\
\hline $\begin{array}{l}\text { Elation } \\
\text { friendly } \\
\text { cheerful }\end{array}$ & $\begin{array}{l}\text { tired } \\
\text { sleepy }\end{array}$ & $\begin{array}{l}\text { indifferent } \\
\text { undisturbed }\end{array}$ \\
\hline pleasant & $\begin{array}{l}\text { Activity } \\
\text { initiative }\end{array}$ & $\begin{array}{l}\text { Cognition } \\
\text { forgetful }\end{array}$ \\
\hline Shyness & active & confused \\
\hline suspicious & spontaneous & losing something \\
\hline withdrawn & $\begin{array}{l}\text { talkative } \\
\text { interest in daily activity }\end{array}$ & losing touch with reality \\
\hline Mood & dependent & Contact \\
\hline $\begin{array}{l}\text { irritable } \\
\text { moody }\end{array}$ & alert & $\begin{array}{l}\text { liking one's company } \\
\text { interested }\end{array}$ \\
\hline relaxed & Anxiety & contact with fellow residents \\
\hline unreasonable & restless & contact with nursing staff \\
\hline well tempered & nervous & cooperative \\
\hline difficult & anxious & \\
\hline
\end{tabular}

(2) Visual Memory Span from the WMS-R (Wechsler, 1984). This task can be considered as a non-verbal equivalent of the Digit Span test.

(3) The Eight Words Test (Lindeboom and Jonker, 1989 ) is used as a measure of auditory, verbal long-term memory. This task provides measures of Immediate Recall, Delayed Recall, and Recognition.

(4) Face Recognition from the Rivermead Behavioural Memory Test (RBMT) provides a measure of visual, non-verbal long-term memory (Wilson et al., 1987).

(5) Picture Recognition from the RBMT provides a measure of visual, verbal long-term memory (Wilson et al., 1987).

(6) Word Fluency from the Groninger Intelligence Test, a Dutch intelligence test (Snijders and Verhage, 1983). This task measures the ability of subjects to retrieve familiar information from semantic memory by asking to name as many animals and occupations as possible, each during $1 \mathrm{~min}$.

The subjects of the experimental and control groups did these tests the day before and the day after a period of 6 weeks during which the experimental and placebo treatments were applied. In addition, a follow-up measurement was performed 6 weeks after the experimental and placebo treatments had ended.

The tests were administered by an independent investigator who was not informed about the groups to which the subjects belonged.

\section{Observation scales}

Two observation scales were used in order to evaluate the effects of treatment on various aspects of affective behaviour.

One observation scale was a standard factoranalysed rating scale for elderly patients [Beoordelingsschaal voor Oudere Patiënten (BOP); Van der Kam et al., 1971], a revision of the Stockton Geriatric Rating Scale (Meer and Baker, 1966). This scale has been divided into six subscales, each consisting of a varying number of items. The subscales are (1) Need of Help (BOP1); (2) Aggressiveness (BOP2); (3) Physical Invalidity (BOP3A); (4) Depressed Behaviour (BOP3B); (5) Mental Invalidity (BOP3C); and (6) Inactivity (BOP4). The administration of the BOP scales took place a day before and a day after the 6 week period of treatments.

The other observation scale was a Behaviour Inventory, constructed by the authors. This inventory includes 12 main traits, which each consist of a varying number of items, with a total of 44 items (see Table I). The main traits are depression, elation, shyness, mood, anger, tiredness, activity, anxiety, conscience, indifference, cognition, and contact. Each item was measured on a 5-point rating scale, ranging from -2 to +2 . A score of -2 meant that, in comparison with 6 weeks ago, a particular item was applicable to the patient to a much lesser extent; a score of +2 indicated the opposite. Scores in between implied a moderate change or no change (score of zero). This inventory was administered twice. The first adminis- 
tration occurred 6 weeks after the experimental and placebo treatments were applied. The second evaluation took place following a 6 week period without treatment.

All subjects were evaluated by a nursing staff consisting of 10 nurses trained to observe patients' behaviour. They did not know which subjects belonged to which group. The nursing staff filled in the two inventories together, which resulted in a joint judgement (consensus).

\section{Stimulation}

Activation of, for example, the hippocampus and hypothalamus by a combined treatment with shortterm TENS and tactile stimulation is supposed to be transmitted by afferent nerve fibres, i.e. A-beta, Adelta, and C fibres (Howson, 1978). The conditions (stimulation parameters) under which these three types of afferent nerve fibres in patients with $A D$ could be optimally stimulated are based upon animal studies dealing with pain suppression (analgesia). Because peripheral tactile and electrical stimulation seems to activate the same afferent nerve fibres (Howson, 1978; Guieu et al., 1990, 1991), animal studies dealing with analgesia by either type of stimulation are suitable for providing parameters such as location, intensity, and duration of the stimulation. The stimulation parameters will be discussed separately for short-term TENS, tactile stimulation, and placebo stimulation. Duration of stimulation will be discussed simultaneously for all three types of stimulation.

Short-term TENS. Frequency and intensity. A-beta fibres respond very well to high frequency stimulation, i.e. $100 \mathrm{~Hz}$ with an intensity just above threshold (Omura, 1987; Guieu et al., 1990, 1991). Interestingly, one study showed activation of A-beta fibres after low frequency stimulation $(2 \mathrm{~Hz})$ with an intensity of twice the threshold for visible muscular twitches (Jørum and Shyu, 1988). A frequency of $100 \mathrm{~Hz}$ is supposed to have an effect on both the serotonergic system (Cheng and Pomeranz, 1979; Young et al., 1985) and the cholinergic system (Youing et al., 1985; Romo et al., 1987). Activation of A-delta and C fibres is usually caused by low frequency stimulation (less than $10 \mathrm{~Hz}$ ) with an intensity well above threshold (Wolf, 1978; Pauser, 1980; Mokha et al., 1985; Soric and Devlin, 1985; Jones and Gebhart, 1987), triggering strong muscular contractions (Duranti et al., 1988). A frequency of $2 \mathrm{~Hz}$ is supposed to have an effect on the noradrenergic neurotransmitter system (Cedarbaum and Aghajanian, 1978). To activate all three types of afferent nerve fibres resulting in stimulation of the serotonergic, cholinergic, and noradrenergic neurotransmitter systems, high frequency and low frequency stimulation had to be combined in one treatment. For this purpose, patients of the experimental group were treated with an electro-stimulator, type Premier 10s. This stimulator generates transcutaneous electro-stimulation which consists of asymmetric biphasic square impulses, applied in bursts of trains, nine pulses per train, with an internal frequency of $160 \mathrm{~Hz}$, a repetition rate of $2 \mathrm{~Hz}$, and a pulse width of $40 \mu \mathrm{s}$. This type of TENS is known as BURST-TENS (Eriksson et al., 1979). The intensity of the stimulation triggered visible muscular twitches which were painless. A flickering green light placed on the electro-stimulator indicated stimulation.

Location. The patient was seated in a chair. Two $2 \times 3 \mathrm{~cm}$ (height $\times$ width) standard carbon rubber electrodes with gel were fixed with tape on the patient's back between Th1 and Th5, one on each side of the spinal column. Because asymmetric biphasic impulses were used, one electrode had a negative pole, the other a positive one. In order to divide the possible effect of BURST-TENS equally over both sides of the spinal column, the poles were changed daily.

Tactile stimulation. Intensity. Based on the findings that A-delta, A-beta, and C fibres respond optimally to differential intensities of stimulation (Cedarbaum and Aghajanian, 1978; Wolf, 1978; Janko and Trontelj, 1980; Pauser, 1980; Coffey and Mahon, 1982; Bushnell et al., 1991), the intensity of stimulation used in the present study varied from just above to well above threshold. By means of feedback from the patients, i.e. by asking the patients what they perceived, it was checked whether this varying level of intensity actually took place.

Location. Tactile stimulation by massage was carried out on the patient's back between Th5 and Th12.

Placebo stimulation. In order to provide the control group with a placebo treatment, sham electrostimulation was applied, i.e. without administering any current. For this purpose, a transcutaneous electro-stimulator, type Premier 10s, was used. The subjects in the control group were told that the stimulator gave off signals which they could not feel and that the stimulation began at the moment a green light started to flicker on the apparatus.

Location. Two $2 \times 3 \mathrm{~cm}$ (height $\times$ width) rubber electrodes with gel were placed on the back of the hand, one electrode on each hand, on the surface of 
the skin where the index finger and thumb converge. This area of the hand is innervated by the ramus superficialis of the radial nerve (Kaada, 1976), is often used in studies concerning peripheral stimulation mechanisms (Pertovaara and Hämäläinen, 1982), and was also applied as a control method in our earlier studies (Scherder et al., 1994a, b, 1995). In addition, the authenticity of the placebo stimulation was increased by a flickering green light on the apparatus.

Duration of stimulation. Studies concerning analgesia indicate that a peripheral stimulation time of 20 30 min per treatment is necessary to provide analgesia (Eriksson et al., 1979; Dlin et al., 1980; Wolf et al., 1981; Youing et al., 1985; Robaina et al., 1989; Guieu et al., 1990). In order to evaluate the analgesic effect of peripheral stimulation and to maintain the acquired relief from pain, these studies report a total duration of a treatment period of at least 4 weeks (Lampe, 1978; Frampton, 1982). Based on these data, the patients of the experimental and control group were offered a stimulation time of $30 \mathrm{~min}$ per day for a 6 week period. In order to obtain a similar interpersonal communication in both groups during the session, the same therapist (E.S.) applied both the experimental and placebo treatments.

\section{Data analyses}

Neuropsychological tests. The pre-test scores were submitted to a multivariate analysis of variance (MANOVA) in order to verify that no difference existed between the two groups at the start of the experiment. Cognitive testing took place immediately before the 6 weeks of stimulation (pre-test, T1), after this period (post-test, T2), and following another period of 6 weeks without stimulation (delayed, T3). There are two important questions of investigation in this study. (1) Could the experimental group, compared to the control group, maintain or even improve their memory functions after the 6 weeks of stimulation? To answer this question, an analysis of the test scores from T1 and T2 (pre/post) is required. (2) Do effects, if any, last over a period of 6 weeks without further stimulation? To answer this question we compared T1 and T3 (pre/delayed). For both of these questions, an analysis of variance with a repeated measures design was applied for each neuropsychological test, with Group as a between-subjects factor and Time [T1/T2 (pre/post) and T1/T3 (pre/delayed), respectively] as a within-subjects factor. These data analyses were carried out by means of the MANOVA procedure in the SPSS-PC program (Norusis, 1988). The Group by Time interaction is the effect of interest in this study. In case of significant interaction effects, post-hoc comparisons (paired $t$-tests) were made contrasting the measurements on $\mathrm{T} 1 / \mathrm{T} 2$ and $\mathrm{T} 1 / \mathrm{T} 3$ for each group.

Observation scales. The BOP scale has been constructed primarily to evaluate a patient's behaviour at fixed moments, which were the day before (pretreatment scores, T1) and the day after the treatment period of 6 weeks (post-treatment scores, T2). The difference between the two measurements $\mathrm{T} 1$ and $\mathrm{T} 2$ serves to indicate whether a change has occurred in the patient's behaviour. Since the Behaviour Inventory, on the other hand, is primarily aimed at recording a possible change in affective behaviour, the first evaluation took place after the treatment period of 6 weeks (post-treatment scores, T2). In order to evaluate whether the treatment effects could be maintained over a 6 week period without treatment (delayed scores, T3), an overall effect score was calculated for each item to assess the situation after 12 weeks. The overall effect score was calculated by adding the post-treatment (T2) and the delayed scores (T3). The SPSS-PC program was used for statistical analyses, including one-factor analysis of covariance (ANCOVA), $t$-tests, and Mann-Whitney $U$-tests (Norusis, 1988). A $p$ value of $<0.05$ was considered to be significant.

\section{RESULTS}

\section{Neuropsychological tests}

The test scores showed a normal pattern of distribution and no outliers were found in the sample. The results of the MANOVA on the pre-test scores showed no significant differences between the experimental and control groups on any of the pre-test scores. This finding was confirmed by univariate analyses.

For the experimental as well as for the control group, the pre-, post-, and delayed test scores (means and standard errors of the mean) on the various neuropsychological tests are presented in Table II.

Table III shows the results of the pre/post (T1/T2) analyses of variance. No significant Group by Time interaction effects were found. The Group by Time interactions for the Recognition subtest of the Eight Words Test, for Face Recognition and Picture Recognition tended to be significant. Post-hoc comparisons for the Recognition subtest of the Eight Words Test revealed that, in contrast to the experimental group, the performance of the control group declined significantly after treatment. Furthermore, the experimental 
TABLE II. Means and standard errors of the mean of the neuropsychological tests

\begin{tabular}{|c|c|c|c|c|c|c|c|c|c|c|c|c|}
\hline \multirow[t]{3}{*}{ Tests } & \multicolumn{6}{|c|}{ Experimental group } & \multicolumn{6}{|c|}{ Control group } \\
\hline & \multicolumn{2}{|c|}{ Pre } & \multicolumn{2}{|c|}{ Post } & \multicolumn{2}{|c|}{ Delayed } & \multicolumn{2}{|c|}{ Pre } & \multicolumn{2}{|c|}{ Post } & \multicolumn{2}{|c|}{ Delayed } \\
\hline & Mean & S.E. & Mean & S.E. & Mean & S.E. & Mean & S.E. & Mean. & S.E. & Mean & S.E. \\
\hline Digit Span & 4.00 & 0.47 & 4.31 & 0.57 & 3.31 & 0.37 & 4.19 & 0.47 & 4.00 & 0.51 & 4.31 & 0.46 \\
\hline $\begin{array}{l}\text { Visual Memory } \\
\text { Eight Words Test }\end{array}$ & 4.19 & 0.28 & 4.75 & 0.45 & 4.31 & 0.49 & 3.81 & 0.44 & 3.88 & 0.41 & 4.25 & 0.41 \\
\hline Immediate Recall & -0.25 & 0.41 & 0.00 & 0.38 & 0.12 & 0.40 & 0.25 & 0.49 & 0.25 & 0.25 & 0.38 & 0.32 \\
\hline Delayed Recall & 0.25 & 0.25 & 0.25 & 0.25 & 0.25 & 0.25 & 0.13 & 0.13 & 0.13 & 0.13 & 0.25 & 0.16 \\
\hline Recognition & 7.25 & 1.81 & 7.50 & 2.03 & 7.00 & 1.56 & 7.50 & 1.30 & 5.00 & 1.56 & 7.50 & 1.76 \\
\hline Face Recognition & 4.25 & 1.28 & 7.50 & 1.18 & 5.75 & 0.88 & 4.00 & 1.77 & 3.75 & 1.16 & 4.00 & 1.07 \\
\hline Picture Recognition & 9.25 & 1.85 & 11.75 & 1.44 & 12.25 & 1.22 & 10.50 & 1.95 & 8.75 & 1.64 & 9.25 & 2.14 \\
\hline Verbal Fluency & 2.06 & 0.32 & 2.19 & 0.41 & 1.94 & 0.55 & 3.06 & 0.66 & 2.88 & 0.51 & 3.06 & 0.55 \\
\hline
\end{tabular}

TABLE III. Results of the Group by Time interaction effects of the pre/post (T1/T2) analyses of variance, and the paired $t$-test post-hoc comparisons for the significant interactions

\begin{tabular}{|c|c|c|c|c|c|c|}
\hline \multirow[b]{3}{*}{ Tests } & & & \multicolumn{4}{|c|}{$t$-tests (T1/T2) } \\
\hline & \multicolumn{2}{|c|}{ ANOVA } & \multicolumn{2}{|c|}{ Experimental } & \multicolumn{2}{|c|}{ Control } \\
\hline & $F(1,14)$ & $p$ & $t(7)$ & $p$ & $t(7)$ & $p$ \\
\hline Digit Span & 1.17 & N.S. & & & & \\
\hline $\begin{array}{l}\text { Visual Memory } \\
\text { Eight Words Test }\end{array}$ & 0.91 & N.S. & & & & \\
\hline Immediate Recall & 0.30 & N.S. & & & & \\
\hline Delayed Recall & 0.00 & N.S. & & & & \\
\hline Recognition & 3.08 & 0.10 & 0.28 & 0.79 & -1.93 & 0.05 \\
\hline Face Recognition & 4.21 & 0.06 & 3.05 & 0.01 & -0.19 & 0.43 \\
\hline Picture Recognition & 3.93 & 0.07 & 1.42 & 0.10 & -1.43 & 0.10 \\
\hline Verbal Fluency & 0.59 & N.S. & & & & \\
\hline
\end{tabular}

group performed significantly better on Face Recognition whereas the control group did not. As for Picture Recognition, treatment tended to improve the performance in the experimental group, whereas the performance in the control group declined with a significant tendency.

Pre/delayed (T1/T3) analyses revealed that only the improvement in Picture Recognition could be maintained during the treatment-free period $[\mathrm{F}(14)=4.37 ; p<0.06]$.

\section{BOP scale}

For the experimental group as well as for the control group, the mean pre- and post-treatment scores on the BOP scale are presented in Table IV. The pretreatment scores on the BOP scale revealed no significant differences between the two groups as indicated by $t$-tests.

Treatment effects were examined by means of ANCOVA, separately for each subscale, with the post-treatment scores (T2) as dependent variable and the pre-treatment scores (T1) as covariate (see Table
IV). Significant treatment effects were observed for Need of Help (BOP1) and Physical Invalidity (BOP3A). A slight tendency for significance was found for Mental Invalidity (BOP3C). As can be seen from Table IV, the significant treatment effects for Need of Help and Physical Invalidity indicate that the experimental group's behaviour improved whereas that of the control group declined. The slightly significant tendency for Mental Invalidity might be explained by the fact that the experimental group's behaviour improved whereas that of the control group did not change during the treatment period. No treatment effects were found for Aggressiveness (BOP2), Depressed Behaviour (BOP3B) or Inactivity (BOP4).

\section{Behaviour Inventory}

The effect of treatment was analysed by administering the Behaviour Inventory after a treatment period of 6 weeks (post-treatment scores, T2). In order to investigate whether treatment improved overall affective behaviour, a Total Score of Changes was calculated 
TABLE IV. Means and analyses of covariance of the BOP Geriatric Observation Scale (pre-test as covariate)

\begin{tabular}{|c|c|c|c|c|c|c|c|}
\hline \multirow[b]{2}{*}{ BOP subscales } & \multicolumn{2}{|c|}{ Treatment } & \multicolumn{2}{|c|}{ Placebo } & \multicolumn{3}{|c|}{ ANCOVA } \\
\hline & Pre & Post & Pre & Post & $F$ & df & $p$ \\
\hline Need of help & 12.13 & 9.88 & 10.75 & 11.25 & 8.72 & 1,14 & 0.01 \\
\hline Aggressiveness & 1.50 & 1.00 & 2.38 & 1.88 & 0.49 & 1,14 & 0.50 \\
\hline Physical Invalidity & 1.63 & 1.25 & 1.38 & 1.75 & 8.45 & 1,14 & 0.01 \\
\hline Depressed Behaviour & 3.00 & 3.00 & 2.25 & 2.25 & 0.27 & 1,14 & 0.61 \\
\hline Mental Invalidity & 1.25 & 0.88 & 1.63 & 1.63 & 2.96 & 1,14 & 0.11 \\
\hline Inactivity & 8.13 & 8.38 & 7.88 & 8.25 & 0.01 & 1,14 & 0.93 \\
\hline
\end{tabular}

by summing the recorded scores of all items employed in the Behaviour Inventory. The Total Score of Changes appeared not to be significant (see Table V). Subsequently, a possible treatment effect for each main trait separately was analysed by summing up the recoded scores of all items belonging to this particular trait. None of the main traits showed a significant treatment effect. The main trait Depression tended to be significant, which implies that patients of the experimental group improved in Depression whereas the control group declined. More specifically, two items belonging to the main trait Depression showed a significant treatment effect, i.e. the items "dejected" $[t(14)=-1.78 ; p<0.05]$ and "gloomy" $[t(14)=-2.16 ; p<0.03]$. Furthermore, a slight tendency for significance was observed for the main trait Mood $[t(14)=-1.32 ; p<0.11]$. Within the main trait Mood, three items showed a significant treatment effect, i.e. "irritable" $[t(14)=-2.26$; $p<0.03$ ], "moody" [ $t(14)=-1.82 ; p<0.05]$, and "well tempered" $[t(14)=-2.12 ; p<0.03]$. Also the main trait Conscience tended to be significant. Unexpectedly, however, an improvement in Conscience was observed in the control group whereas the experimental group showed a slight decrement. Particularly, a significant placebo effect was observed for the item "concentrated" $[t(14)=1.82 ; p<0.05]$ which belongs to this main trait.

The results of the pre-delayed analyses showed that the observed treatment effects did not persist in the period without treatment.

\section{Present results compared with those of previous studies}

In order to evaluate whether a combination of shortterm TENS and massage exceeded the treatment effects obtained by applying short-term TENS (Scherder et al., 1994a) and massage (Scherder et al., 1994b, 1995) separately, the results of the two latter studies and those of the present study are shown in Table VI. Only significant or nearly significant effects ( $p$ values) are presented.
As Table VI shows, short-term TENS, massage, and a combination of both types of stimuli have a beneficial influence on the Recognition subtest of the Eight Words Test, Face Recognition, and Picture Recognition. Massage shows additional effects on Verbal Fluency and Visual Memory. This latter effect results also from short-term TENS. Comparing the effects of treatment on the BOP scales, the most striking finding is that all three types of stimulation significantly decreased Need of Help (BOP1) and Physical Invalidity (BOP3A). Evaluating the results of the Behaviour Inventory, it is obvious that only tendencies for the main traits Depression and Mood were observed after combined stimulation. In contrast, the single application of short-term TENS and massage show extensive improvements in various main traits of this observation scale.

\section{DISCUSSION}

Patients who had undergone simultaneous application of short-term TENS and massage tended to improve on some aspects of verbal (Picture Recognition) and non-verbal (Face Recognition) long-term memory. The performance of the experimental group on the Recognition subtest of the Eight Words Test (verbal long-term memory) stayed at the same level during the treatment period whereas the performance of the control group on this task declined significantly during this period.

Comparing these results with those obtained after separate application of short-term TENS and massage (see Table VI), it seems as if all three types of stimulation had a beneficial effect on verbal and non-verbal long-term memory (Recognition subtest of the Eight Words Test, Picture Recognition, and Face Recognition). However, compared to combined stimulation, massage appears to have an additional effect on word fluency (Verbal Fluency) and nonverbal short-term memory (Visual Memory). The latter effect was also observed after short-term TENS. For a better performance on the Visual Memory 
TABLE V. Means and $t$-tests of the main traits of the Behaviour Inventory after a treatment period of 6 weeks

\begin{tabular}{lcrrr}
\hline Main traits & $\begin{array}{c}\text { Experimental } \\
\text { Post }\end{array}$ & $\begin{array}{c}\text { Control } \\
\text { Post }\end{array}$ & \multicolumn{2}{c}{$t$-test } \\
\cline { 4 - 5 } & & & $t(14)$ & $p$ \\
\hline Depression & 1.13 & -0.50 & 1.70 & 0.06 \\
Elation & 1.00 & 0.38 & 0.89 & 0.20 \\
Shyness & 0.00 & 0.00 & 0.00 & 0.50 \\
Mood & 0.88 & -0.25 & 1.32 & 0.11 \\
Anger & 0.13 & 0.25 & -0.61 & 0.28 \\
Tiredness & -0.38 & -0.25 & -0.13 & 0.45 \\
Activity & 0.38 & 0.25 & 0.10 & 0.46 \\
Anxiety & 0.25 & 0.25 & 0.00 & 0.50 \\
Conscience & -0.25 & 0.38 & -1.53 & 0.08 \\
Indifference & 0.00 & 0.13 & -1.001 & 0.32 \\
Cognition & -0.75 & -0.50 & -0.25 & 0.40 \\
Contact & 1.50 & 0.75 & 0.89 & 0.19 \\
Total Score of Changes & 3.88 & 0.88 & 0.62 & 0.27 \\
\hline
\end{tabular}

${ }^{1}$ Mann-Whitney $U$-test (Z-score), due to no variance in the treatment group.

TABLE VI. (Nearly) significant effects ( $p$-values) on memory and affective behaviour of AD patients by combined short-term TENS and massage treatment, compared with those of short-term TENS and massage applied separately

\begin{tabular}{|c|c|c|c|}
\hline & $\begin{array}{l}\text { Short-term } \\
\text { TENS }\end{array}$ & Massage & $\begin{array}{c}\text { Short-term TENS } \\
\text { + Massage }\end{array}$ \\
\hline \multicolumn{4}{|l|}{ Tests } \\
\hline \multicolumn{4}{|l|}{ Digit Span } \\
\hline Visual Memory & 0.08 & 0.02 & \\
\hline \multicolumn{4}{|l|}{$\begin{array}{l}\text { Eight Words Test } \\
\text { Immediate Recall } \\
\text { Delayed Recall }\end{array}$} \\
\hline Recognition & 0.05 & 0.04 & 0.10 \\
\hline Face Recognition & 0.01 & 0.02 & 0.06 \\
\hline Picture Recognition & 0.001 & 0.07 & 0.07 \\
\hline Verbal Fluency & & 0.02 & \\
\hline \multicolumn{4}{|l|}{ BOP scales } \\
\hline $\begin{array}{l}\text { Need of Help (BOP1) } \\
\text { Aggressiveness (BOP2) }\end{array}$ & 0.01 & 0.04 & 0.01 \\
\hline Physical Invalidity (BOP3A) & 0.01 & 0.04 & 0.01 \\
\hline Depressed Behaviour (BOP3B) & & & \\
\hline Mental Invalidity (BOP3C) & & 0.10 & 0.11 \\
\hline Inactivity (BOP4) & 0.07 & 0.06 & \\
\hline \multicolumn{4}{|l|}{ Behaviour Inventory } \\
\hline Depression & 0.06 & 0.01 & 0.06 \\
\hline Elation & 0.06 & & \\
\hline Shyness & 0.03 & 0.06 & \\
\hline Mood & 0.03 & 0.02 & 0.11 \\
\hline \multicolumn{4}{|l|}{ Anger } \\
\hline Tiredness & 0.11 & & \\
\hline Activity & 0.05 & & \\
\hline Anxiety & & 0.11 & \\
\hline Conscience & & & 0.08 \\
\hline \multicolumn{4}{|l|}{ Indifference } \\
\hline Cognition & 0.07 & & \\
\hline Contact & & 0.07 & \\
\hline Total Score of Changes & 0.03 & 0.01 & \\
\hline
\end{tabular}


task, patients had to improve storing, reversing, and producing of visual information. A higher score on Verbal Fluency implied that patients' capacity for retrieval of familiar, categorized information from their memory store had improved.

Significant treatment effects of simultaneous application of short-term TENS and massage were observed on two BOP scales, i.e. Need of Help (BOP1) and Physical Invalidity (BOP3A), while Mental Invalidity (BOP3C) tended to be significant. These findings suggest that after treatment, patients participated more in activities of daily life. They improved in eating and getting dressed more independently and showed a better personal orientation and orientation in place. Moreover, patients' restlessness through the day and night declined. However, combined stimulation did not appear to enhance social interaction with fellow residents (Inactivity, BOP4), as was observed after separate application of short-term TENS and massage (Table VI). Comparing combined stimulation with short-term TENS and massage separately further showed a remarkable similarity between the effects of these three types of stimulation on Need of Help (BOP1) and Physical Invalidity (BOP3A).

Analyses of the Behaviour Inventory suggest that simultaneously applied short-term TENS and massage exerted no significant influence on the main traits. Only the main traits Depression and Mood showed significant tendencies, suggesting that patients who had undergone treatment felt less dejected, less gloomy, less irritable, less moody, and better tempered. Comparing the effects of the three types of stimulation on the Behaviour Inventory, it is obvious that the striking effects of massage and short-term TENS did not match the moderate influence of combined stimulation on the main traits Depression and Mood.

Taken together, the results as presented in Table VI led us to conclude that the positive effects of combined short-term TENS and massage on cognition, affective behaviour, and daily activities of $\mathrm{AD}$ patients do not exceed those observed after each type of stimulation applied separately. Nevertheless, it should be noted that the present results have an additional value because of their clinical relevance. The burden of caregivers was eased for the majority of the patients, as reported by the nursing staff.

One may only speculate about the mechanisms underlying the findings of the present study. One explanation for the finding that the combination of stimuli did not give a better result might be an inverted U-shaped stimulus-effect relationship, as has been reported for example for cholinesterase inhibitors (for review, see Pomponi et al., 1990). In this case, both lowering the strength of the stimulus or increasing it would lead to less effective results (Thal et al., 1983; Sweeney et al., 1990). A similar inverted U-shaped dose-response curve was observed after administration of central nervous stimulants such as nicotine (Parrott and Craig, 1992).

It should be emphasized that the results of the present study provide no direct evidence that the locus coeruleus-noradrenergic system and the nucleus raphe dorsalis-serotonergic system are indeed activated by combined stimulation with subsequent activation of the hippocampus and hypothalamus of $A D$ patients. In addition, the present results must be considered with caution, particularly in view of the relatively small number of subjects.

So far, the most effective type of peripheral nerve stimulation of $\mathrm{AD}$ patients seems to be short-term TENS and massage applied separately. It might be useful to investigate whether applying both types of stimuli in succession instead of simultaneously could increase the magnitude of the treatment effects.

\section{Acknowledgements}

The authors are very grateful to the staff members of the St Jacob for their hospitality and help in conducting the study, and to Xytron Medical for their kind permission to use their apparatus. We would like to thank J.J. Alkema for his invaluable assistance with the administration of the neuropsychological tests. We are also very grateful to T.L. Holdstock, $\mathrm{PhD}$, for his suggestions about the application of tactile stimulation and for his critical reading of the manuscript, D.F. Swaab, MD, $\mathrm{PhD}$, for his constructive comments, and W.T.P. Verweij for revising the English.

\section{REFERENCES}

Bobillier P, Seguin S, Petitjean F et al. (1976) The raphe nuclei of the cat brain stem: a topographical atlas of their efferent projections as revealed by autoradiography. Brain Research, 113, 449-486.

Bushnell MC, Marchand S, Tremblay N et al. (1991) Electrical stimulation of peripheral and central pathways for the relief of musculoskeletal pain. Canadian Journal of Physiology and Pharmacology, 69, 697-703.

Carpenter GA and Grossberg S (1993) Normal and amnesic learning, recognition and memory by a neural model of cortico-hippocampal interactions. Trends in Neuroscience, 16, 131-137.

Cedarbaum JM and Aghajanian GK (1978) Activation of the locus coeruleus neurons by peripheral stimuli: modulation by a collateral inhibitory mechanism. Life Sciences, 23, 1383-1392.

Cheng RSS and Pomeranz B (1979) Electro-acupuncture analgesia could be mediated by at least two pain-relieving mechanisms: endorphin and non-endorphin systems. Life Sciences, 25, 1957-1962.

Coffey GH and Mahon MV (1982) Pain: theories and a new approach to treatment. Journal of the National Medical Association, 74, 147-153. 
Deelman BG, Maring W and Otten V (1989) De CST, een gestandaardiseerde screeningsmethode voor dementie. In: Gezond zijn is ouder worden (Eds JJF Schroots, A Bouma, CPA Braam et al.), pp. 163-170. Van Gorkum, Assen.

Dlin RA, Benmair J and Hanne N (1980) Pain relief in sports injuries-application of TENS to acupuncture points. International Journal of Sports Medicine, 1, 203206.

Dudar JD, Whishaw IQ and Szerb JC (1979) Release of acetylcholine from the hippocampus of freely moving rats during sensory stimulation and running. Neuropharmacology, 18, 673-678.

Duranti R, Pantaleo T and Bellini F (1988) Increase in muscular pain threshold following low frequency-high intensity peripheral conditioning stimulation in humans. Brain Research, 452, 66-72.

Dutar P, Lamour Y and Jobert A (1985) Activation of identified septohippocampal neurons by noxious peripheral stimulation. Brain Research, 328, 15-21.

Eriksson MBE, Sjölund BH and Nielzen S (1979) Long term results of peripheral conditioning stimulation as an analgesic measure in chronic pain. Pain, 6, 335-347.

Foote SL, Bloom FE and Aston-Jones G (1983) Nucleus locus coeruleus: new evidence of anatomical and physiological specificity. Physiological Reviews, 63, 844914.

Frampton VM (1982) Pain control with the aid of transcutaneous nerve stimulation. Physiotherapy, 68, 77-81.

Guieu R, Tardy-Gervet M, Blin O et al. (1990) Pain relief achieved by transcutaneous electrical nerve stimulation and/or vibratory stimulation in a case of painful legs and moving toes. Pain, 42, 43-48.

Guieu R, Tardy-Gervet M and Roll J (1991) Analgesic effects of vibration and transcutaneous electrical nerve stimulation applied separately and simultaneously to patients with chronic pain. Canadian Journal of Neurological Sciences, 18, 113-119.

Hamilton M (1960) A rating scale for depression. Journal of Neurology, Neurosurgery, and Psychiatry, 23, 56-62.

Harley CW (1987) A role for norepinephrine in arousal, emotion and learning?: limbic modulation by norepinephrine and the Kety hypothesis. Progressive Neuro-Pharmacology and Biological Psychiatry, 11, 419-458.

Howson DC (1978) Peripheral neural excitability. Implications for transcutaneous electrical nerve stimulation. Physical Therapy, 58, 1467-1473.

Huan-Ji D and Yan-fang C (1976) Localization of central structures involved in descending inhibitory effect of acupuncture on viscero-somatic reflex discharges. Scientia Sinica, XIX, 137-148.

Jacobs BL, Heym J and Trulson MK (1981) Behavioral and physiological correlates of brain serotonergic unit activity. Journal de Physiologie, Paris, 77, 431-436.

Janko M and Trontelj J (1980) Transcutaneous electrical nerve stimulation: a micro-neurographic and perceptual study. Pain, 9, 219-230.

Jones SL and Gebhart GF (1987) Spinal pathways mediating tonic, coerulospinal and raphe-spinal descending inhibition in the rat. Journal of Neurophysiology, 58, 138159.

Jørum E and Shyu BC (1988) Analgesia by low-frequency nerve stimulation mediated by low-threshold afferents in rats. Pain, 32, 357-366.
Kaada B (1976) Neurophysiology and acupuncture: a review. Advances in Pain Research Therapy, 1, 733-741.

Lampe GN (1978) Introduction to the use of transcutaneous electrical nerve stimulation devices. Physical Therapy, 58, 1450-1454.

Legoratti-Sanchez MO, Guevara-Guzman R and SolanoFlores LP (1989) Electrophysiological evidences of bidirectional communication between the locus coeruleus and the suprachiasmatic nucleus. Brain Research Bulletin, 23, 283-288.

Lindeboom J and Jonker C (1989) Amsterdamse DementieScreeningstest. Handleiding. Swets \& Zeitlinger, Lisse.

McKhann G, Drachman D, Folstein M et al. (1984) Clinical diagnosis of Alzheimer's Disease: Reports of the NINCDS-ADRDA work-group under the auspices of the Department of Health and Human Services task force on Alzheimer's disease. Neurology, 34, 939-944.

Meer B and Baker JA (1966) The Stockton Geriatric Rating Scale. Journal of Gerontology, 21, 392-403.

Mokha SS, McMillan JA and Iggo A (1985) Descending control of spinal nociceptive transmission. Actions produced on spinal multireceptive neurones from the nuclei locus coeruleus (LC) and raphe magnus (NRM). Experimental Brain Research, 58, 213-226.

Norusis MJ (1988) Statistical Packages for the Social Sciences, SPSS/PC + . McGraw-Hill, New York.

Omura Y (1987) Basic electrical parameters for safe and effective electro-therapeutics [electro-acupuncture, TES, TENMS (or TEMS), TENS and electro-magnetic field stimulation with or without drug field] for pain, neuromuscular skeletal problems, and circulatory disturbances. Acupuncture and Electro-Therapeutics Research, The International Journal, 12, 201-225.

Parrott AC and Craig D (1992) Cigarette smoking and nicotine gum $(0.2$ and $4 \mathrm{mg})$ : effects upon four visual attention tasks. Neuropsychobiology, 25, 34-43.

Pauser G (1980) Neurophysiologische und Neuropharmakologische Untersuchungen über (mögliche) Mechanismen der peripheren Stimulationsanalgesie. Wiener Klinische Wochenschrift, 92, 1-20.

Pertovaara MD and Hämäläinen MA (1982) Vibrotactile threshold elevation produced by high-frequency transcutaneous electrical nerve stimulation. Archives of Physical Medicine and Rehabilitation, 63, 597-600.

Petrov T, Krukoff TL and Jhamandas JH (1992) The hypothalamic paraventricular and lateral parabrachial nuclei receive collaterals from raphe nucleus neurons: a combined double retrograde and immunocytochemical study. Journal of Comparative Neurology, 318, 18-26.

Pfeiffer E (1975) A short portable mental status questionnaire for the assessment of organic brain deficit in elderly patients. Journal of the American Geriatric Society, 23, 433-441.

Pomponi M, Giacobini E and Brufani M (1990) Present state and future development of the therapy of Alzheimer disease. Aging, 2, 125-153.

Raadsheer FC, Hoogendijk WJG, Stam FC et al. (1994) Increased numbers of corticotropin-releasing hormone expressing neurons in the hypothalamic paraventricular nucleus of depressed patients. Neuroendocrinology, 60, 436-444.

Robaina FJ, Rodriquez JL, de Vera JA et al. (1989). Transcutaneous electrical nerve stimulation and spinal cord stimulation for pain relief in reflex sympathetic 
dystrophy. Stereotactic and Functional Neurosurgery, 52 , 53-62.

Romo R, Morot Gaudry-Talarmain Y, Chéramy A et al. (1987) Different effects of electrical stimulation of the mesencephalic and pontine reticular formation on the release of dopamine and acetylcholine in the cat caudate nucleus. Neuroscience Letters, 78, 57-62.

Rossor M (1988) Neurochemical studies in dementia. In: Handbook of Psychopharmacology (Eds LL Iversen, SD Iversen and SH Snijder), pp. 107-130. Plenum Press, New York.

Salzmann E (1992) Importance of the hippocampus and parahippocampus with reference to normal and disordered memory function. Fortschritte der Neurologie-Psychiatrie, 60, 163-176.

Saper CB (1988) Chemical neuroanatomy of Alzheimer's disease. In: Handbook of Psychopharmacology (Eds LL Iversen, SD Iversen and SH Snijder), pp. 131-156. Plenum Press, New York.

Scheltens Ph, Leys D, Barkhof F et al. (1992) Atrophy of medial temporal lobes on MRI in 'probable' Alzheimer's disease and normal ageing: diagnostic value and neuropsychological correlates. Journal of Neurology, Neurosurgery, and Psychiatry, 55, 967-972.

Scherder EJA, Bouma A and Steen AM (1992) Influence of transcutaneous electrical nerve stimulation on memory in patients with dementia of the Alzheimer type. Journal of Clinical and Experimental Neuropsychology, 14, 951960.

Scherder EJA, Bouma A and Steen AM (1994a) Effects of short-term transcutaneous electrical nerve stimulation on memory and affective behaviour in patients with probable Alzheimer's disease. Behavioural Brain Research Accepted.

Scherder EJA, Bouma A and Steen AM (1994b) Effects of peripheral tactile stimulation on memory in patients with Alzheimer's Disease. The American Journal of Alzheimer's Care and Related Disorders and Research Accepted.

Scherder EJA, Bouma A and Steen AM (1994c) Effects of peripheral tactile nerve stimulation on affective behaviour of patients with probable Alzheimer's disease. The American Journal of Alzheimer's Care and Related Disorders and Research Accepted.

Snijders JTh and Verhage F (1983) Groninger Intelligentie Test. Swets \& Zeitlinger, Lisse.
Soric R and Devlin M (1985) Transcutaneous electrical nerve stimulation. Postgraduate Medicine, 78, 101-106.

Swaab DF, Hofman MA, Lucassen PJ et al. (1993) Functional neuroanatomy and neuropathology of the human hypothalamus. Anatomy and Embryology, 187, 317-330.

Sweeney JE, Bachman ES and Coyle JT (1990) Effects of different doses of galanthamine, a long-acting acetylcholinesterase inhibitor, on memory in mice. Psychopharmacology, 102, 191-200.

Thal IJ, Fuld PA, Masur DM et al. (1983) Oral physostigmine and lecithin improve memory in Alzheimer's disease. Annals of Neurology, 13, 491-496.

Tucker DM and Williamson PA (1984) Asymmetric neural control systems in human self-regulation. Psychological Review, 91, 185-215.

Van der Kam P, Mol F and Wimmers MFHG (1971) Beoordelingsschaal voor Oudere Patiënten. Van Loghum Slaterus, Deventer.

Vertes R (1991) A PHA-L analysis of ascending projections of the dorsal raphe nucleus in the rat. Journal of Comparative Neurology, 313, 643-668.

Wechsler D (1984) Wechsler Memory Scale Revised. The Psychological Corporation, New York.

Wilson B, Cockburn J and Baddeley A (1987) The Rivermead Behavioural Memory Test. Thames Valley Test Company, Titchfield.

Wolf SL (1978) Perspectives on central nervous system responsiveness to transcutaneous electrical nerve stimulation. Physical Therapy, 58, 1443-1448.

Wolf SL, Gersh MR and Rao VR (1981) Examination of electrode placements and stimulating parameters in treating chronic pain with conventional transcutaneous electrical nerve stimulation (TENS). Pain, 11, 37-47.

Youing W, Jie W and Shuangkun W (1985) The role of acetylcholine in the rat brain and its effect on 5-hydroxytryptamine metabolism during electro-acupuncture analgesia. Journal of Traditional Chinese Medicine, 4, 297300.

Zweig RM, Ross CA, Hedreen JC et al. (1988) The neuropathology of aminergic nuclei in Alzheimer's disease. Annals of Neurology, 24, 233-242.

(Received 27 June 1994; accepted as revised 1 December 1994) 


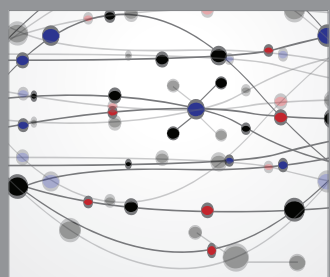

The Scientific World Journal
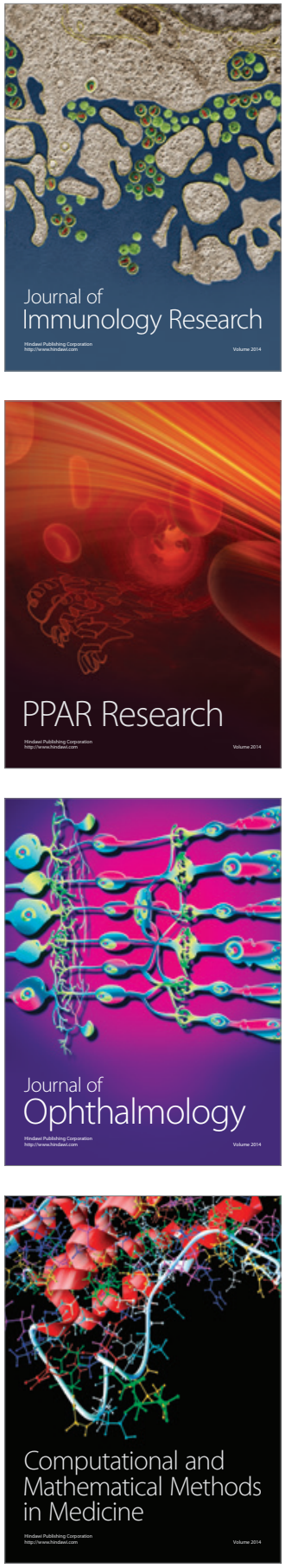

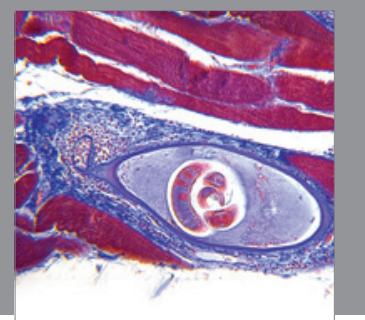

Gastroenterology

Research and Practice
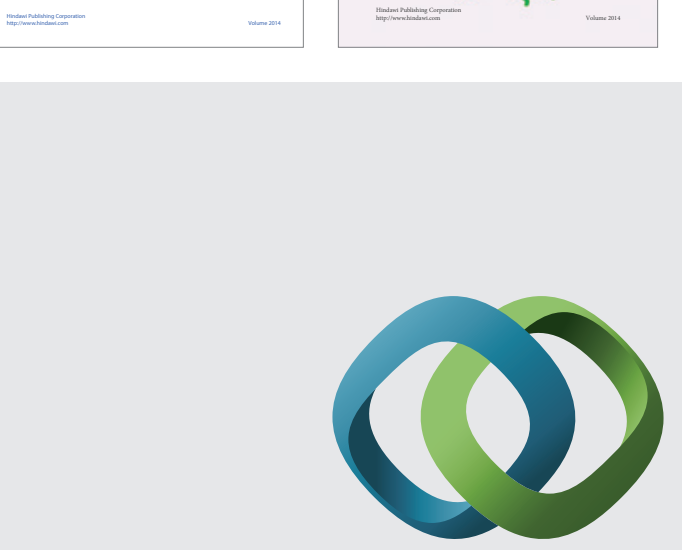

\section{Hindawi}

Submit your manuscripts at

http://www.hindawi.com
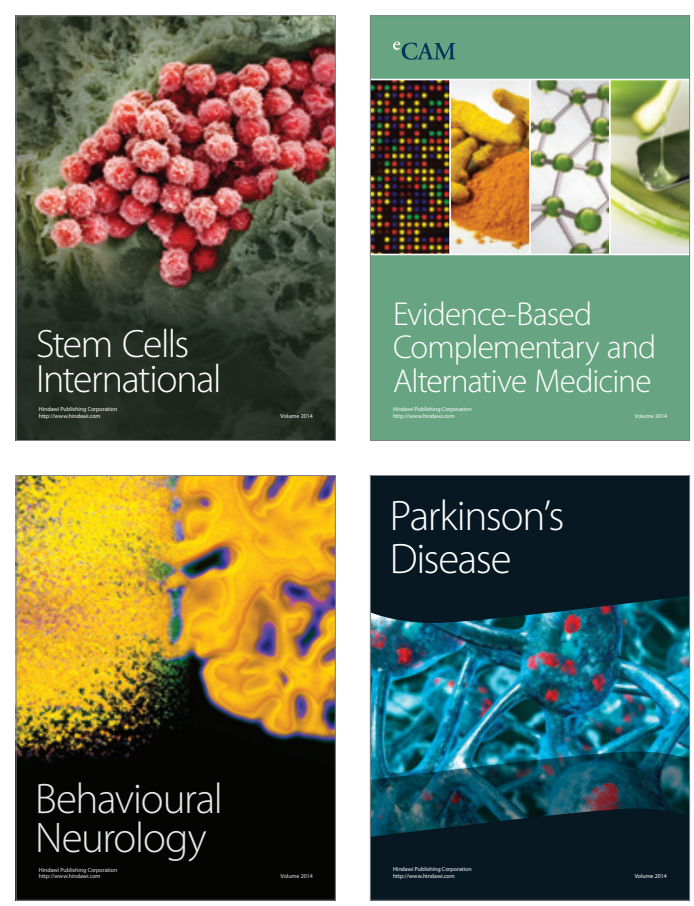

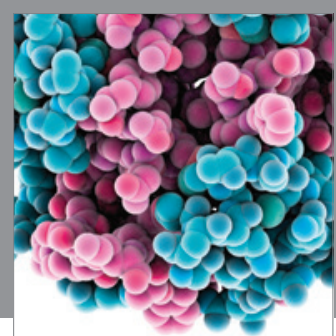

Journal of
Diabetes Research

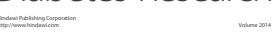

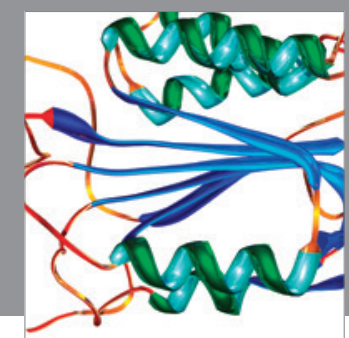

Disease Markers
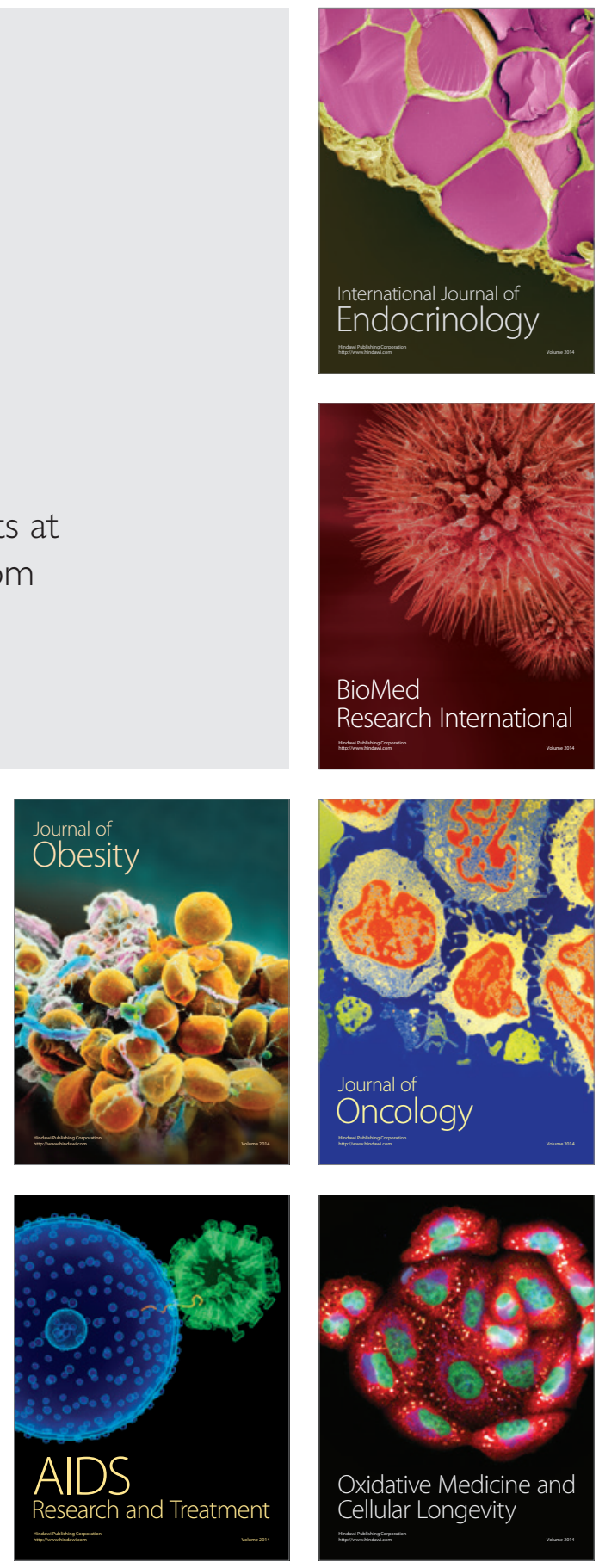